\title{
Identity of the nurse in the society of rationalism
}

\section{José Ramón Martínez-Riera' \\ ORCID: 0000-0002-4926-6622}

'Universidad de Alicante. Alicante, Spain.

How to cite this article:

Martínez-Riera JR. Identity of the nurse in the society of rationalism. Rev Bras Enferm [Internet]. 2019;72(5):1127-8. doi: http://dx.doi.org/10.1590/0034-7167-2019720501
We, nurses, suffer and, to a large extent, continue to suffer the influence of medicine in the development of both our discipline and professional scientific development.

In Health Systems we perform as nurses, clearly phagocytosed by medical science and focusing on diseases, biology, technology and care, and where the hospital is the center of knowledge and unique scientific development of medicine, it is very difficult to develop the nursing paradigm, which is so distant from these approaches.

As a result of this medical colonization, we generally imitate a model that is not ours and in which the disease is a mild or severe alteration of the normal functioning of an organism or of some of its parts due to an internal or external cause. This model distances us from our true objective, which is the attention to health problems, understood as problems related to a state or process related to health and manifested by a person, a family or a community. In other words, care is focused on the disease and away from the person, the family and their environment, as opposed to a comprehensive, integrated and integrative care under a physical, psychic, social and spiritual perspective, incorporating the family and its surroundings.

Nurses nowadays and in the future need scientific evidence in which they can build and strengthen nursing science and on which to base their autonomous practice. It is not intended to generate confrontation with doctors, but rather to articulate a joint action in which the true interest is focused on people, families and the community, not in the areas of corporate power of any particular discipline. It is therefore an issue of working in a transdisciplinary way ${ }^{(1)}$, abandoning the rigidity of competency frameworks, in order to adapt them to the reality that, at all times, requires the health teams' care, beyond whom they must correspond.

Science is, by definition, interested above all by doctors in generalizations and predictions. Consciously or not, we have values, we make choices and it is important to be clear about them. Our care is always related to helping a person or a group of people to meet their needs. It is true that nurses learn from experience, but it is essential that they learn and grow professionally, becoming familiar with the nursing paradigm and transferring theory to practice. Therefore, the image of the nurse is inseparable from her evolution as a discipline and has evolved extraordinarily from the perspective of her own orientations and concepts centered on care, person, health, environment, practice, training, research, and management.

Currently, nurses have to respond to multiple health problems, many of which are complex and, above all, individual (poverty, migration, environment, gender violence, etc.). However, in general, the nurse-person relationship is superficial, focused on the disease rather than on the health problem, with the necessary comprehensive approach. Care humanization is essential to not abandon the essential characteristic of care ${ }^{(2)}$. However, there is the paradox that on many occasions what is being demanded by colonized health organizations, as we have said, by medicine, is the provision of technological nurses. Furthermore, the nurse loses her focus or her autonomous contribution focused on care to provide well-being, comfort, safety, humanistic counseling, as well as adequate and agreed specific care. Nevertheless, if we take into account 
the transcendence of care, the relationship with the person and the family, and assuming their responsibility to be autonomous, nurses are and will be absolutely essential in the community.

It should be borne in mind that society is dynamic, changes and proposes new settings and new demographic, epidemiological, social and political realities that foresee a future reserved for nursing care. The person is, or at least should be, considered in its entirety. Nurses should focus their care in a comprehensive, integrated and integrative way. Put another way, spirituality, consciousness, self-concept, way of life, well-being, feelings, emotions, connections, relationships, etc. are dimensions that, in nursing practice, should be taken into account. Nursing care is a complex, non-linear, evolving reality that needs to be identified in order to be transferred to the discipline and to the profession and henceforward to society.

On the other hand, it is necessary to emphasize that we are immersed in the society of rationalism. It is inferred that technology can respond to any problem. While it is true that technology is part of our existence, the issue is to know what to do with it to prevent it from destroying our identity. Although it sounds like an outdated truism in nursing, lack of ethics and dehumanization are becoming more and more evident. Nevertheless, it is necessary to structure our autonomous action to prevent the evolution of nursing as a science linked to medicine, to let go of its fundamental essence and that of values and self-care that give it singularity. It is necessary to identify that the added value we offer is focused on the human response to the person's need for care, whether in health or illness, and is also offered with quality.

Derived from all this, permanently the recognition that society has of nurses will oscillate based on the balance between technique and nursing care. These, on the other hand, will allow us to identify and value ourselves as professionals with a recognizable paradigm that identifies, visibilizes and values us both in the scientific community and in society in general ${ }^{(3)}$.

\section{REFERENCES}

1. Pérez Matos NE, Setién Quesada E. La interdisciplinariedad y la transdisciplinariedad en las ciencias: una mirada a la teoría bibliológicoinformativa. ACIMED [Internet]. 2008[cited 2019 Apr 29];18(4). Available from: http://scielo.sld.cu/pdf/aci/v18n4/aci31008.pdf

2. Correa Zambrano ML. La humanización de la atención en los servicios de salud: un asunto de cuidado. Rev Cuid [Internet]. 2016 [cited 2019 Apr 29];7(1):1210-8. Available from: http://dx.doi.org/10.15649/cuidarte.v7i1.300

3. Albar MJ, Sivianes-Fernández M. Percepción de la identidad profesional de la enfermería en el alumnado del grado. Enferm Clínica. 2016;26(3):194-8. doi: 10.1016/j.enfcli.2015.10.006 